\title{
Effects of operative hysteroscopy with anti-adhesive solution in the patients who have abnormal uterine bleeding or intrauterine lesions ${ }^{*}$
}

\author{
Tae-Hee Kim, Hae-Hyeog Lee ${ }^{\#}$, Soo-Ho Chung, Junsik Park
}

Department of Obstetrics and Gynecology, Soonchunhyang University College of Medicine, Bucheon, Republic of Korea

Email: "hhl22@chol.com, "hhl22@schmc.ac.kr

Received 20 March 2013; revised 20 April 2013; accepted 28 April 2013

Copyright (c) 2013 Tae-Hee Kim et al. This is an open access article distributed under the Creative Commons Attribution License, which permits unrestricted use, distribution, and reproduction in any medium, provided the original work is properly cited.

\section{ABSTRACT}

Objective: The purpose of this study was to evaluate the efficacy, safety, and benefits of hysteroscopic surgery in the treatment of dysfunctional uterine bleeding (DUB) or intrauterine lesions causing uterine bleeding. Methods: This study prospectively enrolled 100 patients who underwent operative hysteroscopy in tertiary referral university center because of uterine bleeding due to endometrial polyps or uterine submucosal leiomyomas diagnosed by transvaginal ultrasonogram. Indications for the operative hysteroscopies included abnormal uterine bleeding (AUB), ultrasound findings indicative of intrauterine lesions, and DUB. After operative hysteroscopic management, we inserted anti-adhesive solution, sodium hyaluronate and carboxymethyl cellulose into the uterine cavity. Results: Operative hysteroscopy was a successful procedure in 100 of 100 cases $(100 \%)$ but it needed to be repeated in three cases with large uterine submucosal leiomyoma and after two endometrial polypectomy. Mean duration of the procedure was 23.2 minutes (range 5 - 67) and postoperative hospital stay was 7 hours (range 3 - 48). Most common indication was DUB (39\%), submucosal leiomyoma was $21 \%$, and endometrial polyp was $17 \%$. There were five cases with postoperative uterine bleeding and none with fluid overload syndrome. During postoperative follow-up (3 - 28 months) the majority of patients $(\mathbf{9 0 / 1 0 0}, \mathbf{9 0 \%})$ were free of symptoms. Conclusion: Hysteroscopic procedure is an effective and safe method for the management of benign intracavitary pathology or the treatment of dysfunctional uterine bleeding. Although sodium hyaluronate and car-

\footnotetext{
Conflict of interest: The authors of the present manuscript declare that no conflict of interest.

${ }^{\#}$ Corresponding author.
}

boxymethyl cellulose seems to be effective in the prevention of adhesion in uterine cavity, further study will be needed to prove the effectiveness of anti-adhesive solution.

Keywords: Hysteroscopy; Uterine Hemorrhage; Menorrhagia

\section{INTRODUCTION}

Abnormal uterine bleeding (AUB) is one of the most frequent menstrual problems. It includes heavy and/or prolonged periods (menorrhagia) and any form of irregular bleeding through vagina. It is usually due to abnormalities of reproductive tract which may be benign (endometrial polyp, submucosal leiomyomas, adhesions, endometrial hyperplasia etc.) or malignant or it may be due to infection. Dysfunctional uterine bleeding (DUB) has been used to describe abnormal bleeding for which no specific cause has been found.

Minimal invasive surgery is a major advance in patient care and as a result hysteroscopic surgery is playing an important role in the management of menstrual disorders and intrauterine lesions that cause abnormal uterine bleeding. The advantages of hysteroscopy offer many women an opportunity to achieve a surgical solution to their bleeding problem that retains their uterus, are devoid of incisions, and which can be performed in a short-stay setting [1-4].

In this study, we analyzed the results of 100 operative hysteroscopies performed for abnormal uterine bleeding due to intrauterine lesions or severe dysfunctional uterine bleeding.

\section{MATERIALS AND METHODS}

One hundred patients were enrolled and were examined 
in the department of obstetrics and gynecology, a university hospital in the period from February 2009 to February 2011. All patients gave written consent before the procedure and the study was approved by the Institutional Review Board.

Indications for the operative hysteroscopy included AUB, ultrasound findings indicative of intrauterine lesions, and dysfunctional uterine bleeding (DUB). Exclusive criteria were pregnancy, carcinoma, pelvic inflamematory disease and excessive bleeding. All operative hysteroscopy were performed with the Office Continuous Flow Operative Hysteroscope size 5 (Karl Storz, Tuttlingen, Germany). The uterine cavity was distended with sorbitol with manitol and illumination was provided by a high intensity cold light source or a xenon light source (300 W) via a fiber optic lead. Dilatation of the cervix up to Hegar 11 was performed before the introduction of the resectoscope. Good orientation, identification of the tubal ostia and localization of the lesion was the first step of the procedure. Using a blended cutting and coagulating current of $75-125 \mathrm{~W}$, submucosal leiomyomas and endometrial polyps were resected or a transcervical resection of endometrium was performed. Fluid balance was monitored closely and surgery was stopped when the deficit was $>2.0 \mathrm{~L}$.

In addition, sodium hyaluronate and carboxymethyl cellulose were inserted into the uterine cavity in all cases to prevent intrauterine adhesions. In all the patients, antibiotics were administered postoperatively because of the possibility of intrauterine or pelvic infection. Patients and procedure statistics, side-effects and complication were analyzed using descriptive statistics.

\section{RESULTS}

The mean age of the patients involved in this study was 43.7 years. The presenting symptoms of the women were all uterine bleeding including menorrhagia, metrorrhagia, menometrorrhagia and postcoital bleeding. Patients and procedure statistics are shown in Tables $\mathbf{1}$ and $\mathbf{2}$. All the operations were completed successfully in 100 patients $(100 \%)$ and the indication of the procedure is shown in Table 3.

Hysteroscopic myomectomy was completed success-

Table 1. General characteristics of the patients.

\begin{tabular}{cc}
\hline Variables & Patients \\
\hline Number & 100 \\
Age (years) & $43.7 \pm 7.2$ \\
BMI $\left(\mathrm{kg} / \mathrm{m}^{2}\right)$ & $24.1 \pm 3.52$ \\
Parity & $2.6 \pm 1.4$ \\
\hline
\end{tabular}

BMI: body mass index; Data are given as mean \pm S.D.
Table 2. Procedure and operative statistics.

\begin{tabular}{cc}
\hline & Number of procedure \\
\hline Types of procedures & 100 \\
Myomectomies & 21 \\
Polypectomies & 17 \\
Resection of endometrium & 62 \\
General anaesthesia & 100 \\
Operative time (min) & mean $23.2(5-67)$ \\
Postoperative hospital stay (hours) & mean $7(3-48)$ \\
Complications & 10 \\
Uterine perforation & 0 \\
Fluid overload syndrome & 0 \\
Uterine bleeding & 5 \\
Repeated procedure & 5 \\
\hline
\end{tabular}

Data are given as $\mathrm{n}$ or mean (range).

Table 3. Indication of the operative hysteroscopy.

\begin{tabular}{cc}
\hline Variables & Patients (number) \\
\hline Dysfunctional Uterine Bleeding & 39 \\
Submucosal myoma & 21 \\
Endometrial polyp & 17 \\
Uterine adenomyosis & 7 \\
Endometritis & 5 \\
Endometrial hyperplasia & 3 \\
Others & 8 \\
\hline
\end{tabular}

fully in 21 patients with submucosal fibroids type I or II according to the classification of Wamsteker et al. [4]. Three patients completed the operation with a secondlook operative hysteroscopy after three to six months for resection of the residual myoma. In the two of three cases, the first operation was stopped because of the prolonged duration and because fluid absorption over 2.0 L of Urosol ${ }^{\circledR}$ was noted. These patients did not present fluid overload syndrome. In addition, five patients presented persistent mild to moderate bleeding after the operation, Foley catheter was inserted into the uterine cavity and ballooned with $10 \mathrm{~mL}$ saline, immediately. After one day, Foley catheter was removed and further transfusion was not needed.

Hysteroscopic endometrial polypectomy was completed in 17 patients, successfully. No intraoperative or postoperative complications occurred during or after hysteroscopic endometrial polypectomy. However, two 
patients presented intrauterine mass, 4 - 6 months later and repeated endometrial polypectomy was performed.

Resection of endometrium was performed in 62 patients (DUB 39, uterine adenomyosis 7, endometritis 5, endometrial hyperplasia 3, others 8). There was no persistent or severe bleeding after the operation and fluid overload did not occur. Most of the women (52/62, $83.9 \%$ ) that underwent partial or total resection of endometrium continue to menstruate and present improved symptoms but they reported that their periods were shorter and lighter. The ten patients (5 DUB, 3 uterine adenomyosis, 2 endometritis) continued to present dysmenorrhea and irregular bleeding after the operation. They had counseling about having a hysterectomy or other operative therapy for the relief of their symptoms.

In total, repeated hysteroscopy was performed in 5 patients and there were no findings of intracavitary adhesion. Mean duration of follow-up was 14 months (range 3 - 28). During this period, 90/100 patients (90\%) were free of clinical symptoms like menstrual disorders and abnormal uterine bleeding (Table 4).

\section{DISCUSSION}

Hysteroscopy is a minimally invasive procedure, the use of which has increased over time due to its various advantages. In the present study, as in that of Hulka and Hidlebaugh, the most common indication for performing this procedure was a complaint of abnormal uterine bleeding $[5,6]$. The acute complication rate associated with this procedure in this study is $5.0 \%$, which is similar to that reported elsewhere in the medical literature with rates varying between $0.28 \%$ and $5.2 \%[7,8]$. The main acute complications in the other study were found to be false passage and uterine perforation $(60 \%$ - $83 \%$ of all acute complications) [5-8], which did not occur in our study. Propst et al. report fluid overload as the most common complication [9]. Correlating our data with that reported in other studies, we find hysteroscopy to be a safe and effective minimally invasive procedure with a low rate of complications.

Table 4. Follow-up of symptoms after operative hysteroscopy.

\begin{tabular}{ccc}
\hline Variables & $\begin{array}{c}\text { Patients } \\
\text { (number) }\end{array}$ & $\begin{array}{c}\text { Improved symptoms, n } \\
(\%)\end{array}$ \\
\hline $\begin{array}{c}\text { Dysfunctional Uterine } \\
\text { Bleeding }\end{array}$ & 39 & $34(87.2)$ \\
Submucosal myoma & 21 & $21(100)$ \\
Endometrial polyp & 17 & $17(100)$ \\
Uterine adenomyosis & 7 & $4(57.1)$ \\
Endometritis & 5 & $3(60)$ \\
Endometrial hyperplasia & 3 & $3(100)$ \\
Others & 8 & $8(100)$ \\
\hline
\end{tabular}

The result of this study suggest that hysteroscopic endometrial polypectomy in menstruating women is a safe and successful operation for the majority of patients using the cutting loop of the resectoscope. Similar results from other studies support these findings [10] and resectoscopic endometrial polypectomy have a low recurrence rate and usually no complication [11].

Moreover, hysteroscopic myomectomy is a valuable technique for the treatment of submucous leiomyoma. It has been found to be the most effective method in women with a normal sized uterus with no more than two fibroids [12]. There is a great chance of a successful procedure with a similar proportion of the myoma extending into the myometrium as reported in this study and by other studies as well [4,12]. Long term results have shown high satisfaction rates with improved menstrual syndrome and pregnancy rates [13].

Total or partial resection of endometrium is followed by a reduction in the amount of bleeding with normalizetion of menstrual loss in the majority of patients as is reported in this study. Resection of endometrium procedure is a safe and effective in selected patients and most women undergoing resection of endometrium will avoid hysterectomy [14-16].

So, resection of endometrium is an excellent alternative to hysterectomy in women with dysfunctional uterine bleeding, who have previously failed in medical treatment, or when medical therapy is contraindicated.

In our study, sodium hyaluronate and carboxymethyl cellulose, anti-adhesive solution was inserted into the uterine cavity in all the patients. We could confirm that there was no intrauterine adhesion in 5 patients who underwent a second operative hysteroscopy. It is assumed that we could expect the efficacy of sodium hyaluronate and carboxymethyl cellulose in the prevention of intrauterine adhesions after hysteroscopic surgery. In previous study of Seprafilm, which has the same components as our solution, it has been shown to be safe for use and decrease the incidence of intrauterine adhesion [17]. However, the size of number is small and it is just observational finding. So, to prove and assess its efficacy on adhesion, further studies like case-control and randomized control are needed and long term follow up is necessary.

Our data confirm that hysteroscopic surgery is successful in cases of functional menorrhagia resistant to medical therapy, but also when the uterine cavity is distorted by fibroids or endometrial polyps. The complication rate of this procedure is low, yet requires careful intraoperative and postoperative monitoring of the patients. Although sodium hyaluronate and carboxymethyl cellulose seem to be effective in the prevention of adhesion in uterine cavity, further study will be needed to prove the effectiveness of anti-adhesive solution. 


\section{ACKNOWLEDGEMENTS}

This research is supported by Hanmi Pharmaceutical Company. The authors greatly appreciate Seyeon Jang's work on menuscript English editing of the manuscript.

\section{REFERENCES}

[1] Lethaby, A., Shepperd, S., Cooke, I. and Farquhar, C. (1999) Endometrial resection and ablation versus hysterectomy for heavy menstrual bleeding. Cochrane Database of Systemic Review, 2, Article ID: CD000329.

[2] Weber, A. and Munro, M. (1998) Endometrial ablation versus hysterectomy: STOP-DUB. Medscape Women's Health, 3, 3.

[3] Loffer, F.D. (1990) Removal of large symptomatic intrauterine growths by the hysteroscopic resectoscope. Obstetrics and Gynecology, 76, 836. doi:10.1097/00006250-199011000-00023

[4] Wamsteker, K., Emanuel, M.H. and De Kruif, J. (1993) Transcervical hysteroscopic resection of submucous fibroids for abnormal uterine bleeding: Results regarding the degree of intramural extension. Obstetrics and Gynecology, 82, 736.

[5] Hidlebaugh, D. (1996) A comparison of clinical outcomes and cost of office versus hospital hysteroscopy. The Journal of the American Association of Gynecologic Laparoscopists, 4, 39-45. doi:10.1016/S1074-3804(96)80107-1

[6] Hulka, J.F., Peterson, H.A., Phillips, J.M. and Surrey, M.W. (1995) Operative hysteroscopy: American Association of Gynecologic Laparoscopists’ 1993 membership survey. The Journal of the American Association of Gynecologic Laparoscopists, 2, 131-132. doi:10.1016/S1074-3804(05)80004-0

[7] Cayuela, E., Cos, R., Onbargi, L., Moreno, M., Mellado, F., Heredia, F., et al. (1996) Complications of operative hysteroscopy. Journal of the American Association of Gynecologic Laparoscopists, 3, S6. doi:10.1016/S1074-3804(96)80148-4

[8] Jansen, F.W., Vredevoogd, C.B., Van Ulzen, K., Hermans, J., Trimbos, J.B. and Trimbos-Kemper, T.C. (2000) Complications of hysteroscopy: A prospective, multicenter study. Obstetrics and Gynecology, 96, 266-270. doi:10.1016/S0029-7844(00)00865-6
[9] Propst, A.M., Liberman, R.F., Harlow, B.L. and Ginsburg, E.S. (2000) Complications of hysteroscopic surgery: Predicting patients at risk. Obstetrics and Gynecology, 96, 517-520. doi:10.1016/S0029-7844(00)00958-3

[10] Clark, T.J., Khan, K.S. and Gupta, J.K. (2002) Current practice for the treatment of benign intrauterine polyps: A national questionnaire survey of consultant gynaecologists in UK. European Journal of Obstetrics and Gynecology and Reproductive Biology, 103, 65-67. doi:10.1016/S0301-2115(02)00011-8

[11] Preutthipan, S. and Herabutya, Y. (2005) Hysteroscopic polypectomy in 240 premenopausal and postmenopausal women. Fertility and Sterility, 83, 705-709. doi:10.1016/j.fertnstert.2004.08.031

[12] Emanuel, M.H., Wamsteker, K., Hart, A.A., Metz, G. and Lammes, F.B. (1999) Long-term results of hysteroscopic myomectomy for abnormal uterine bleeding. Obstetrics and Gynecology, 93, 743-748. doi:10.1016/S0029-7844(98)00558-4

[13] Hart, R., Molnár, B.G. and Magos, A. (1999) Long term follow up of hysteroscopic myomectomy assessed by survival analysis. BJOG: An International Journal of $\mathrm{Ob}$ stetrics and Gynaecology, 106, 700-705. doi:10.1111/j.1471-0528.1999.tb08370.x

[14] O’Connor, H., Broadbent, J., Magos, A.L. and McPherson, K. (1997) Medical Research Council randomised trial of endometrial resection versus hysterectomy in management of menorrhagia. Lancet, 349, 897. doi:10.1016/S0140-6736(96)07285-6

[15] O’Connor, H. and Magos, A. (1996) Endometrial resection for the treatment of menorrhagia. New England Journal of Medicine, 335, 151-156. doi:10.1056/NEJM199607183350302

[16] Cooper, K.G., Parkin, D.E., Garratt, A.M. and Grant, A.M. (1999) Two-year follow up of women randomised to medical management or transcervical resection of the endometrium for heavy menstrual loss: Clinical and quality of life outcomes. BJOG: An International Journal of Obstetrics and Gynaecology, 106, 258-265. doi:10.1111/j.1471-0528.1999.tb08240.x

[17] Tsapanos, V.S., Stathopoulou, L.P., Papathanassopoulou, V.S. and Tzingounis, V.A. (2002) The role of Seprafilm $^{\mathrm{TM}}$ bioresorbable membrane in the prevention and therapy of endometrial synechiae. Journal of Biomedical Materials Research, 63, 10-14. doi:10.1002/jbm.10040 